\title{
Chagas' heart disease: gender differences in myocardial damage assessed by cardiovascular magnetic resonance
}

\author{
Antonildes N. Assunção Jr', Michael Jerosch-Herold², Rodrigo L. Melo', Alejandra V. Mauricio ', Liliane Rocha', \\ Jorge A. Torreão ${ }^{1}$, Fabio Fernandes ${ }^{1}$, Barbara M. Ianni ${ }^{1}$, Charles Mady ${ }^{1}$, José A. F. Ramires ${ }^{1}$, Roberto Kalil-Filho ${ }^{1}$ \\ and Carlos E. Rochitte ${ }^{1 *}$
}

\begin{abstract}
Background: Since a male-related higher cardiovascular morbidity and mortality in patients with Chagas' heart disease has been reported, we aimed to investigate gender differences in myocardial damage assessed by cardiovascular magnetic resonance (CMR).

Methods and results: Retrospectively, 62 seropositive Chagas' heart disease patients referred to CMR (1.5 T) and with low probability of having significant coronary artery disease were included in this analysis. Amongst both sexes, there was a strong negative correlation between LV ejection fraction and myocardial fibrosis (male $r=0.64$, female $r=0.73$, both $P<0.001$ ), with males showing significantly greater myocardial fibrosis $(P=0.002)$ and lower LV ejection fraction $(P<0.001)$ than females. After adjustment for potential confounders, gender remained associated with myocardial dysfunction, and $53 \%$ of the effect was mediated by myocardial fibrosis ( $P$ for mediation $=0.004$ ). Also, the transmural pattern was more prevalent among male patients $(23.7 \mathrm{vs} .9 .9 \%, P<0.001)$ as well as the myocardial heterogeneity or gray zone ( 2.2 vs. $1.3 \mathrm{~g}, P=0.003)$.

Conclusions: We observed gender-related differences in myocardial damage assessed by CMR in patients with Chagas' heart disease. As myocardial fibrosis and myocardial dysfunction are associated to cardiovascular outcomes, our findings might help to understand the poorer prognosis observed in males in Chagas' disease.
\end{abstract}

Keywords: Chagas' heart disease, Gender differences, Myocardial fibrosis, Myocardial dysfunction

\section{Background}

Considered a neglected tropical disease, Chagas' disease is caused by a protozoan parasite, Trypanosoma cruzi ( $T$. cruzi) and has recently become a global health concern [1], due to immigration from endemic areas into the developed world [2, 3]. In Latin America, Chagas' heart disease is still a major cause of heart failure despite a drop in incidence in the last decades [4].

Patients with Chagas' heart disease have a poorer prognosis in comparison to other cardiomyopathies and, in particular, male gender has been associated to a

\footnotetext{
* Correspondence: rochitte@incor.usp.br

'Heart Institute, InCor, University of Sao Paulo Medical School, Cardiovascular Magnetic Resonance and Computed Tomography Sector, Av. Dr. Enéas de Carvalho Aguiar, 44, Andar AB, Cerqueira César, São Paulo, SP 05403-000, Brazil

Full list of author information is available at the end of the article
}

higher mortality rates [5]. The reasons for this worse clinical prognosis remain unclear and, to our knowledge, there is a lack of studies about sex-related differences in myocardial damage in patients with Chagas' heart disease.

Cardiovascular magnetic resonance (CMR) is able to assess the extent of the myocardial fibrosis (MF), which correlates to LV ejection fraction (LVEF) and is a marker of disease severity in Chagas' heart disease [6, 7]. We sought to investigate whether the male gender is associated to greater myocardial damage assessed by CMR.

\section{Methods}

From 2 previous studies [6, 8], 62 adults with chronic Chagas' disease followed at Heart Institute (InCor), referred to CMR, from 2004 to 2012 and with low probability of having severe coronary artery disease (CAD) 
[9] were included in the study. We used a validated high-risk CAD score [9] based on the following clinical characteristics recorded at the time of CMR: age ( -1 to 10 points), male sex (3 points), diabetes (2 points), hypertension (1 point), current smoking (2 points), hypercholesterolemia ( 1 point), family history of CAD ( 2 points), history of peripheral vascular disease (2 points), and chest pain symptoms (0-2 points). Patients who scored $\geq 18$ points were excluded. Other exclusion criteria were previous myocardial infarction and severe valve disease. Patients in whom oral transmission from outbreaks of either beverage or food contaminations was suspected - which has unfortunately emerged in Brazil [10] - were not included in our study. The reason for this exclusion was the potentially more severe course of the disease following oral transmission [11]. The study was approved by the institutional review board for human subject studies, and all patients provided written informed consent.

\section{CMR}

CMR was performed with a $1.5 \mathrm{~T}$ GE CV/i CMR System (Wakeusha Wisconsin). Ventricular function, volumes and mass were obtained from at least 10 short-axis ventricular slices, imaged with a steady state free precession pulse sequence, covering the entire left ventricle. Late gadolinium enhancement (LGE) images were acquired $10-20 \mathrm{~min}$ after an intravenous bolus of $0.2 \mathrm{mmol} / \mathrm{kg}$ of gadolinium-based contrast, with an inversion-prepared gradient echo-sequence. The sequence parameters for cine/LGE imaging were, respectively: repetition time 3.9/7.1 $\mathrm{ms}$, echo time $1.7 / 3.1 \mathrm{~ms}$, flip angle $45^{\circ} / 20^{\circ}$, cardiac phases $20 / 1$, views per segment $8 / 16$ to 32 , matrix $256 \times 128 / 256 \times$ 192, slice thickness $8 / 8 \mathrm{~mm}$, gap between slices $2 /$ $2 \mathrm{~mm}$ and field of view 32 to $38 / 32$ to $38 \mathrm{~cm}$, inversion time none/150 to $250 \mathrm{~ms}$, receiver bandwidth $125 / 31.25 \mathrm{kHz}$, number of excitations $1 / 1$, acquisition every heart beat/every-other heart beat.

\section{Data analysis}

All CMR images were analyzed with the CVI42 software (Circle Cardiovascular Imaging Inc. Calgary, Canada) by a trained observer. End-systolic, end-diastolic LV volumes, LV mass and LV ejection fraction were measured by standard methods [12]. For quantification of myocardial fibrosis (MF), we applied a semiautomatic thresholding technique to the LGE images with a signal intensity (SI) cutoff value of mean +6 standard deviation (SD) (MF: SI $\geq$ meanSI of normal myocardium +6 standard deviation of normal myocardium), which had best agreement with visual analysis. The location and extent of MF were assessed using the American Heart Association (AHA) segment model. Additionally, the pattern of LGE was classified as subendocardial, midwall, subepicardial or transmural. The myocardial heterogeneity or gray zone extent was defined as the myocardial region with pixels SI between meanSI + 6SD and meanSI + 7SD [13-15].

\section{Statistical analysis}

Chi-squared or Fisher-exact tests and two-sample t-tests or Wilcoxon rank sum test for categorical or continuous data, respectively, were performed for comparing baseline characteristics across gender groups. The correlation between MF and LVEF was performed by Spearman's test.

We assumed that MF lies on the causal pathway between gender and myocardial dysfunction in Chagas' disease, as a mediator variable and we tested the following mediation assumptions [16]: gender has a significant effect on MF; gender has a significant effect on LVEF in the absence of the MF; MF has a significant unique effect on LVEF; and the effect of the gender on LVEF shrinks when the MF is added to the model. A Sobel-Goodman test was used to assess whether the amount of mediation effect was statistically significant [17]. After confirming the mediation assumptions, MF was added to the final model and a multivariate linear regression analysis was performed to determine the effect of gender on LVEF adjusted possible confounders. For all univariate and multivariate analysis, we used MF assessed as \% LV mass since the normal population males have significantly greater myocardial mass [18].

All statistical analyses were performed with Stata 13.0 (StataCorp, Texas, USA) and a $P$-value $<0.05$ was considered as statistically significant and all reported $P$-values were two-tailed.

\section{Results}

Clinical characteristics and ventricular remodeling

Patient characteristics are shown in Table 1. In comparison with 38 females (61.3\%), 24 males (38.7\%) had similar mean age $(54 \pm 11$ vs. $55 \pm 11, P=0.55)$ as well as relative low prevalence of CAD risk factors. Although higher in males, both gender groups had low mean high-risk CAD score $(4.3 \pm 1.7$ vs. $1.1 \pm 1.1$, $P<0.001)$. Moreover, 35 of our patients (56\%) had either an invasive or coronary computed tomographic (CT) angiography during their follow-up and none of them had obstructive CAD.

Heart failure symptoms were significantly more frequent and severe among male patients (54\% vs. $29 \%$ New York Heart Association [NYHA] class $>1, P=0.04$ ). Additionally, LV and RV remodeling was more pronounced in male than female patients, with males presenting significantly higher LV/RV dilation, LV mass and lower LV/RV ejection fraction than females. 
Table 1 Characteristics of Patients with Chagas' Heart Disease

\begin{tabular}{|c|c|c|c|}
\hline Characteristics & Male $(n=24)$ & Female $(n=38)$ & $P$-value \\
\hline \multicolumn{4}{|l|}{ Clinical Data } \\
\hline Age - years* & $54(11)$ & $55(11)$ & 0.55 \\
\hline Body mass index $\left[\mathrm{kg} / \mathrm{m}^{2}\right]^{\dagger}$ & $26(23-29)$ & $25(24-29)$ & 0.55 \\
\hline Obesity - no. (\%) & $5(21)$ & $9(24)$ & 0.79 \\
\hline Hypercholesterolemia - no. (\%) & $9(38)$ & $16(42)$ & 0.72 \\
\hline Diabetes mellitus - no. (\%) & $4(17)$ & $2(5)$ & 0.19 \\
\hline Hypertension - no. (\%) & $8(33)$ & $14(37)$ & 0.78 \\
\hline Current smoker - no. (\%) & $4(17)$ & $2(5)$ & 0.19 \\
\hline CAD score $^{\dagger}$ & $4.3(1.7)$ & $1.1(1.1)$ & $<0.001$ \\
\hline NYHA functional class > I - no. (\%) & $13(54)$ & $11(29)$ & 0.04 \\
\hline NYHA functional class ${ }^{\dagger}$ & $2(1-2.5)$ & $1(1-2)$ & 0.02 \\
\hline GFR $\left[\mathrm{mL} / \mathrm{min} \text { per } 1.73 \mathrm{~m}^{2}\right]^{*}$ & $80(26)$ & $78(26)$ & 0.73 \\
\hline \multicolumn{4}{|l|}{ CMR } \\
\hline LVEDVI $\left[\mathrm{mL} / \mathrm{m}^{2}\right]^{\dagger}$ & $116(97-161)$ & $86(72-108)$ & $<0.001$ \\
\hline LVESVI $\left[\mathrm{mL} / \mathrm{m}^{2}\right]^{\dagger}$ & $74(50-114)$ & $34(28-57)$ & $<0.001$ \\
\hline LV mass index $\left[\mathrm{g} / \mathrm{m}^{2}\right]^{\dagger}$ & $74(63-89)$ & $51(44-61)$ & $<0.001$ \\
\hline $\operatorname{LVEF}[\%]^{\dagger}$ & $37(28-46)$ & $58(47-62)$ & $<0.001$ \\
\hline Aneurysm - no. (\%) & $7(29)$ & $6(16)$ & 0.21 \\
\hline RVESVI $\left[\mathrm{mL} / \mathrm{m}^{2}\right]^{\dagger}$ & $80(63-92)$ & $68(59-74)$ & 0.016 \\
\hline RVEDVI $\left[\mathrm{mL} / \mathrm{m}^{2}\right]^{\dagger}$ & $38(32-50)$ & $25(22-34)$ & $<0.001$ \\
\hline RVEF $[\%]^{\dagger}$ & $50(36-59)$ & $60(52-65)$ & 0.005 \\
\hline Myocardial Fibrosis - yes & $21(87)$ & $27(71)$ & 0.21 \\
\hline Myocardial Fibrosis [grams] $]^{\dagger}$ & $19(9-30)$ & $2.4(0-12)$ & $<0.001$ \\
\hline Myocardial Fibrosis (\% LV mass) ${ }^{\dagger}$ & $12(8-22)$ & $3(0-11)$ & 0.003 \\
\hline 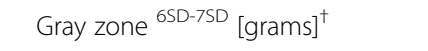 & $2.2(0-4.2)$ & $1.3(0-2.3)$ & 0.003 \\
\hline LGE Patterns* & $3.9(0.9)$ & $3.8(1.0)$ & 0.72 \\
\hline
\end{tabular}

LV denotes left ventricular, LVEF left ventricular ejection fraction, $L V E D V I$ left ventricular end-diastolic volume index, $L V E S V I$ left ventricular end-systolic volume index, NYHA New York Heart Association Functional Classification, RVEF right ventricular ejection fraction, RVEDVI right ventricular end-diastolic volume index, and RVESVI right ventricular end-systolic volume index, LGE late gadolinium enhancement, GFR Glomerular filtration rate. CAD score to assess the clinical probability of having high-risk CAD (low $\leq 7$ points; intermediate, 8-17 points. Patients with high score, $\geq 18$ points, were excluded from this study) [9]. ${ }^{*}$ means (SD) and ${ }^{\dagger}$ medians ( 25 and 75 th centiles). Significant $P$-values $(<0.05)$ are shown in bold

\section{Myocardial fibrosis: presence, extent, distribution and} patterns

Most of patients had MF (77\%) and MF was similarly frequent in male and female patients $(87 \%$ vs. $71 \%, P=0.21)$ (Table 1). The distribution of MF in males and females was similarly frequent in the lateral and inferior LV segments, but significantly different in the septal (basal anterosseptal, $P=0.004$ ) and apical segments (anterior and inferior apical, both $P=0.03$ ) (Fig. 1). The amount of $\mathrm{MF}$ was significantly higher in male patients than in females (median 19.0 vs. $2.4 \mathrm{~g}, P<0.001$, and \% LV mass 12 vs. $3 \%, P=0.003$ ) (Table 1).

Although LGE patterns indistinguishable from CAD were found in 23.1\% of LV segments of patients $(n=151 / 992$ transmural, $n=78 / 992$ subendocardial), non-ischemic patterns were frequently and concomitantly observed (mean $>3$ types of LGE patterns). Only 30\% patients had subendocardial and/or transmural patterns and did not undergo any angiography during follow-up. Interestingly, these potentially ischemic patterns were also found in $24.6 \%$ of LV segments $(n=138 / 560)$ of those patients who had angiography (Fig. 2). Compared to females, males had more frequently transmural ( 23.6 vs. $9.9 \%, P<0.001)$, subepicardial (14.1 vs. $9.2 \%, P=0.02)$ and midwall patterns $(23.8$ vs. $15 \%, P<0.001$ ) (Fig. 3). Likewise, gray zone extent was higher in males (median 2.2 vs. $1.3 \mathrm{~g}, P=0.003$ ) (Table 1 ).

\section{Extent of myocardial fibrosis and LV remodeling}

For all patients, MF (\%LV Mass) was negatively correlated with $\operatorname{LVEF}(r=-0.75, P<0.001)$ and this relationship was comparably strong among males $(r=-0.64, P<$ $0.001)$ and females $(r=-0.73, P<0.001)$, with no indication of an effect modification by gender ( $P$-value for interaction $=0.35)$ (Fig. 4). 


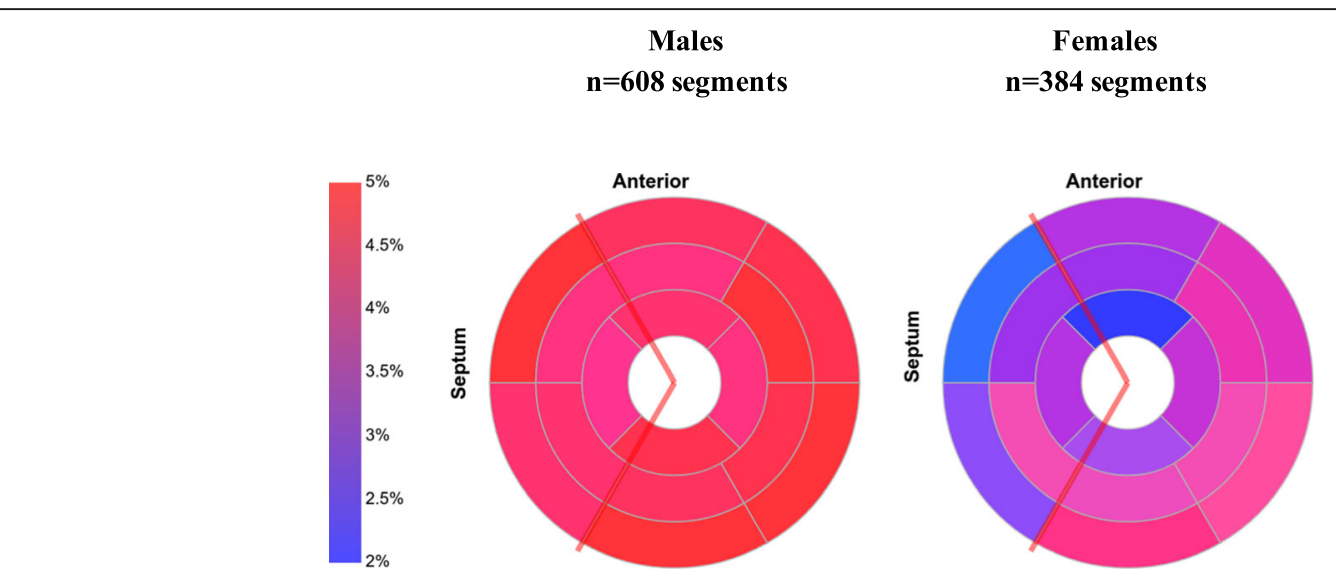

Fig. 1 LGE frequency in male and female patients with Chagas' heart disease. " $n$ " illustrates the total of analyzed segments
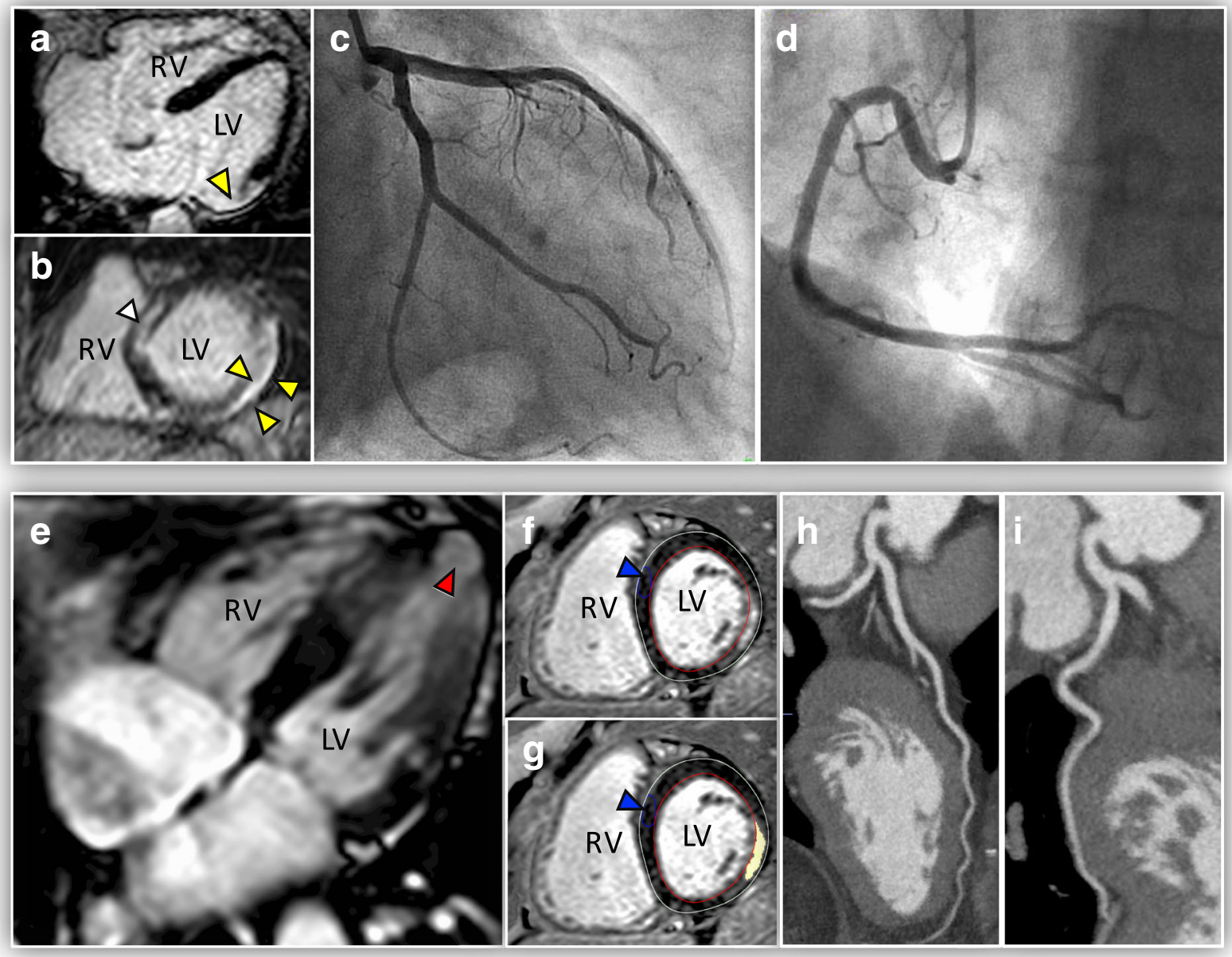

Fig. 2 Examples of CMR, invasive and CT angiography in two representative patients with Chagas' heart disease. First patient (top row): a and $\mathbf{b} C M R$ reveals transmural LGE pattern in the LV lateral wall (yellow arrow) with concomitant septal midwall LGE (white arrow) and, by invasive angiography, (c and d) normal coronary arteries. Second patient (bottom row): (e) cine-CMR image reveals a classical Chagas' heart disease finding, the vorticle aneurysm (red arrow), (f and $\mathbf{g}$ ) LGE reveals subendocardial pattern in the lateral wall (yellow arrow) and, by CT angiography, (h and $\mathbf{i})$ normal coronary arteries. Blue arrow (f and $\mathbf{g}$ ) indicating the region of interest (ROI) for calculating the mean signal intensity (SI) of the reference normal myocardium 


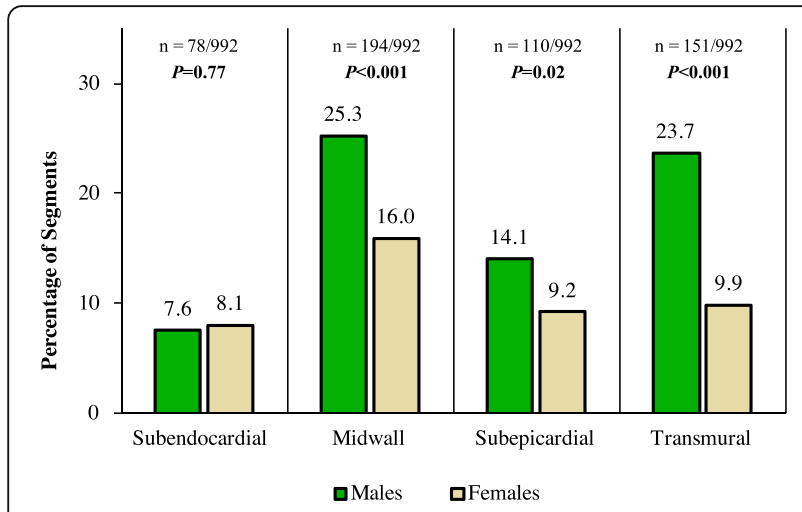

Fig. 3 LGE patterns in male and female patients with Chagas' heart disease. " $n$ " illustrates the absolute frequency of the LGE pattern divided by the total of analyzed segments

Male gender was associated with $165 \%$ higher mean MF (95\% confidence interval [CI] 11 to 320\%) and $30 \%$ lower mean LVEF (95\% CI 18-43\%) compared to female (Fig. 5) in the unadjusted analysis. Although attenuated, the effect of gender on LVEF remained significant $(P=0.02)$ when MF was added as predictor in the model. In the mediation analysis (Figs. 5 and 6), approximately $53 \%$ of the total effect of gender on LVEF was mediated by MF ( $P$-value for mediation analysis $=0.004)$. In a multivariate model to adjust for CAD risk factors, gender remained associated with myocardial dysfunction (Fig. 4).

\section{Discussion}

In this study, we observed sex-related differences in myocardial damage assessed by CMR in patients with Chagas' heart disease: males had significantly more adverse ventricular remodeling and greater MF, as well as different LGE patterns in comparison with females. Moreover, male gender was independently associated with reduced myocardial function and this effect was mostly mediated by MF. These findings might help to understand the observed gender-related differences in the pathogenesis of chronic Chagas' heart disease.

Clinical data have revealed higher mortality among male patients with Chagas' heart disease [5, 19], but this is the first study to demonstrate a significantly higher degree of myocardial damage in vivo. In our study, males patients had lower LVEF by $30 \%$ and higher MF by $165 \%$ on average compared to females. The pathogenesis of chronic Chagas' heart disease is complex, but the inflammatory process with autoimmune reaction is considered the main pathway for myocardial damage, increasing MF, adverse left ventricular remodeling and heart failure severity [20-23]. In mouse models, this immune response against $T$. cruzi infection was more unfavorable in male species, and linked to gonadal hormone differences [24, 25]. MF measured by CMR is a key marker of myocardial damage in non-ischemic cardiomyopathies [26-28] and, likewise, in Chagas' heart disease [6, 8]. For our patients, we found that the association between gender and LVEF was mediated by the amount of MF (53\% of the effect was mediated). Hence, we hypothesized

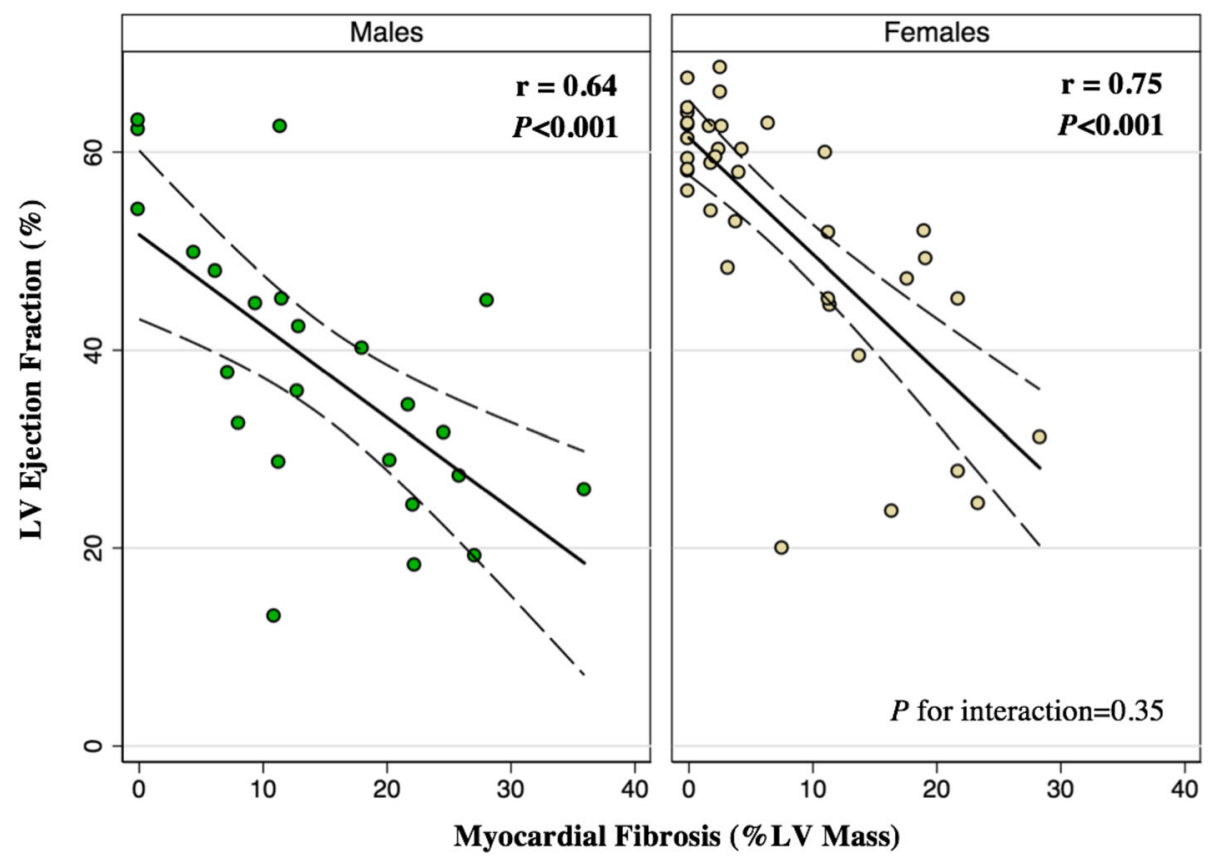

Fig. 4 Sex-specific correlations between MF and LVEF 


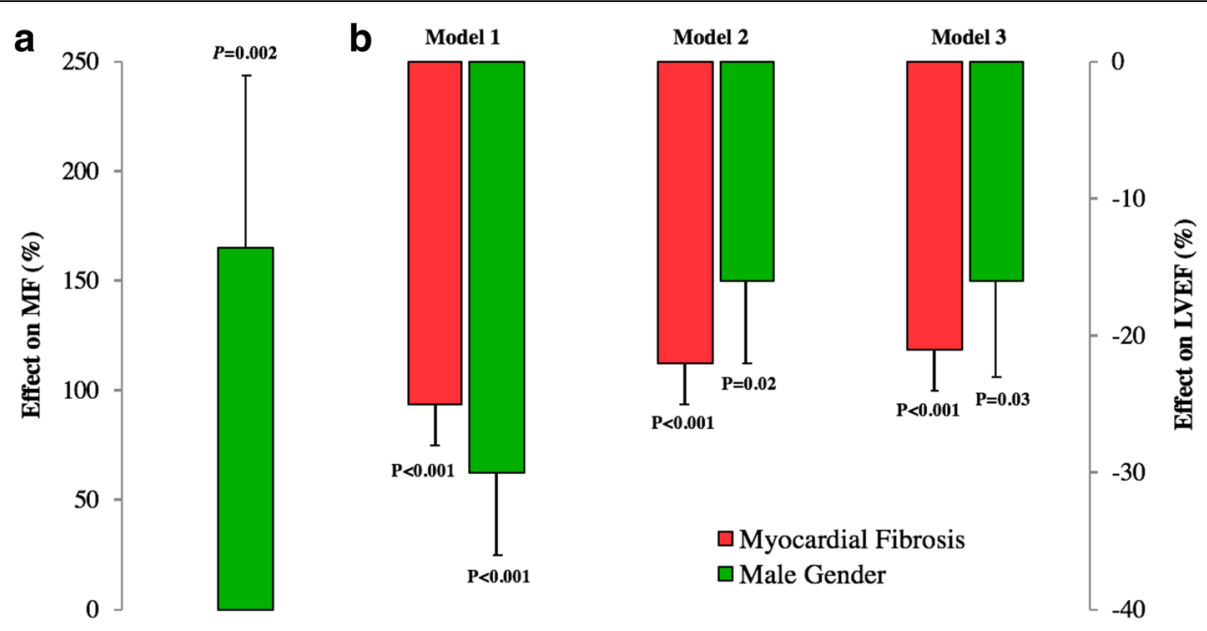

Fig. 5 a Unadjusted effect of gender on MF and $\mathbf{b}$ effects of gender and MF (10-unit increase) on LVEF. Model 1 demonstrates unadjusted effects of gender and MF on LVEF. Model 2 demonstrates the effect of gender on LVEF when adjusted to MF. Model 3 demonstrates the Model 2 additionally adjusted for CAD risk factors (age, diabetes mellitus, hypertension, hypercholesterolemia, body mass index, active smoking). Natural logarithm transformation was used to improve normality and/or homoscedasticity of residuals. The effect was calculated from exponential linear regression coefficients $\left(100 \times\left[e^{\beta}-1\right]\right)$. LVEF was defined as left ventricular ejection fraction, and MF myocardial fibrosis (\%LV Mass)

that male hormone differences might be an exposure to greater myocardial dysfunction in Chagas' pathogenic, being the amount of MF a partly causal pathway.

Furthermore, the presence, size and heterogeneity of MF assessed by CMR have been described as independent predictors for death in ischemic and non-ischemic cardiomyopathies [29-31]. Besides the greater MF amount, we observed the transmural pattern of MF more frequently in males than females (23.7 vs. $9.9 \%, P<0.001)$, as well as higher extent of the gray zones. Interestingly, the transmural pattern has been identified as independent predictor to ventricular tachycardia (4.1-fold greater) in Chagas' heart disease [32]. A higher myocardial heterogeneity and/or larger gray zone extent have also been

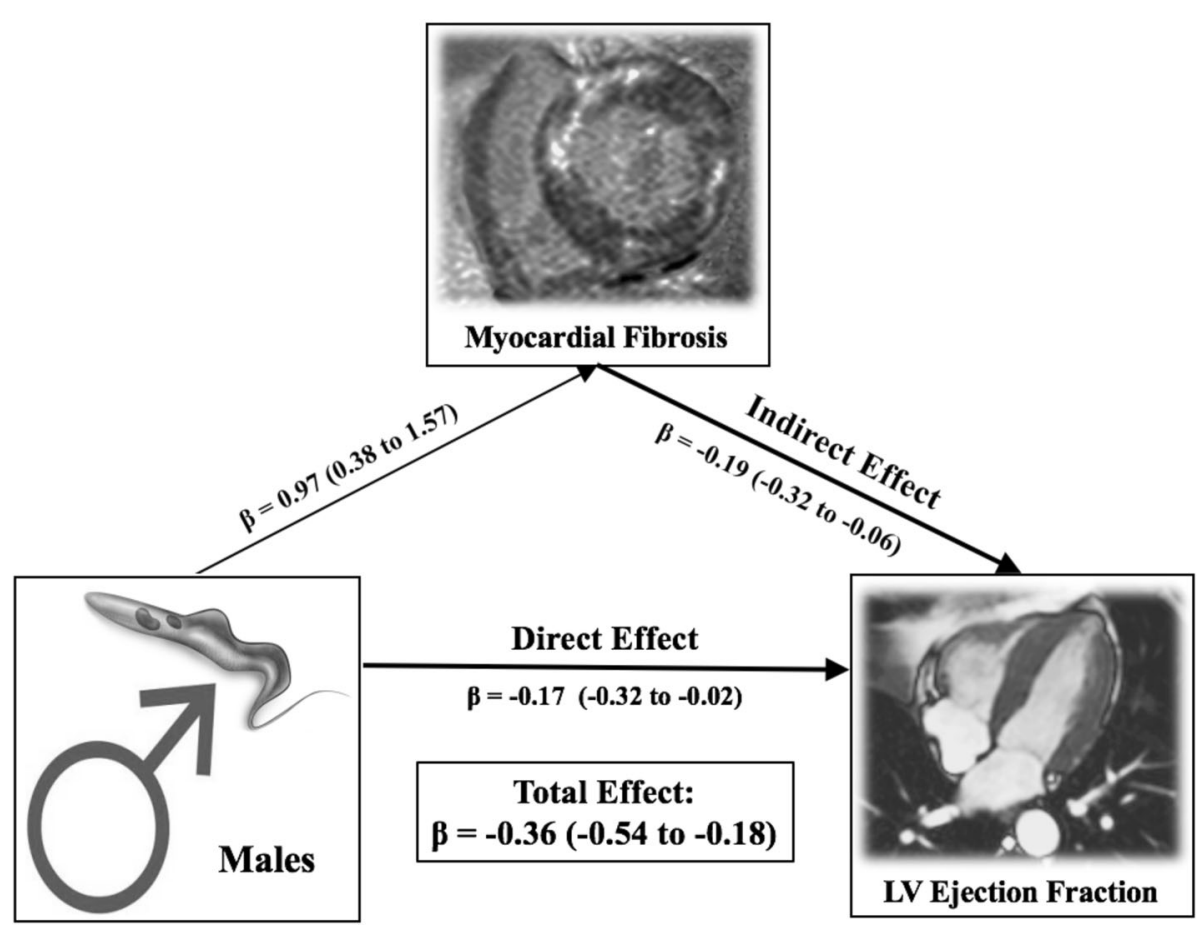

Fig. 6 Mediation model illustrating indirect effect (through MF) and direct effect of gender on LVEF. $\beta$-coefficients of log-level linear regressions of Sobel-Goodman mediation tests. LVEF was defined as left ventricular ejection fraction, and MF myocardial fibrosis (\%LV Mass) 
associated with a higher frequency of adverse cardiac events in non-ischemic cardiomyopathies [33].

There are several limitations in this study. First, although ventricular remodeling and MF have been linked to worse clinical prognosis, this study was not designed to investigate cardiac outcomes. Secondly, as this was a cross-sectional study in Chagas' disease, the time of disease onset remained undetermined, and duration of exposure could influence myocardial damage. However, children aged $<5$ years are most likely to be infected in domiciliary vector transmission (by far, the most common mode of transmission in Brazil in the past) $[1,34]$, and the number of new cases of Chagas' disease have dramatically been decreasing in Brazil since 1990 [1]. Consequently, our male and female patients, who were not different in age at the moment of CMR, may have similar exposure times. Thirdly, we recognize that as the patients have been followed at a tertiary hospital and current guidelines in Brazil do not recommend that patients with Chagas' disease routinely undergo CMR, our results may not apply to other clinical settings and may suffer from some referral bias. Lastly, we did not assess the possible association between hormones and myocardial damage. Therefore our findings should be considered as hypothesis-generating for future studies adequately designed for addressing these issues.

\section{Conclusions}

Our study demonstrated for first time gender-specific differences in myocardial damage in Chagas' heart disease by CMR. Male gender was associated with a higher amount of myocardial fibrosis and worse ventricular remodeling. The relationship of these findings with clinical outcomes in Chagas' heart disease warrants further investigation.

\section{Abbreviations}

AHA: American Heart Association; CAD: Coronary artery disease;

CMR: Cardiovascular magnetic resonance; GFR: Glomerular filtration rate; LGE: Late gadolinium enhancement; LV: Left ventricle; LVEDV: Left ventricular end-diastolic volume; LVEF: Left ventricular ejection fraction; LVESV: Left ventricular end-systolic volume; MF: Myocardial fibrosis; NYHA: New York Heart Association; RV: Right ventricle; RVEDV: Right ventricular end-diastolic volume; RVEF: Right ventricular ejection fraction; RVESV: Left ventricular end-systolic volume; SD: Standard deviation; SI: Signal intensity

\section{Acknowledgements}

Not applicable.

Funding

This work was supported in part by São Paulo Research Foundation (FAPESP), grant number 2010/51900-3 and Zerbini Foundation

Availability of data and materials

Data and materials will be presented upon request.

\section{Authors' contributions}

All authors have substantially contributed to this study: conception and design (ANAJ, CER), carrying out data collection from medical records, CMR acquisition and analysis of the images (JAT, RLM, AVM, LR), analysis of the data and drafting of manuscript (ANAJ, MJH, CER), coordination and revision of manuscript (FF, BMI, CM, JAFR, RKF, CER). All authors have read, revised and given final approval of the submitted manuscript.

\section{Competing interests}

All authors reported no relevant conflicts to the contents of this manuscript.

Ethics approval and consent to participate

This study was approved by the institutional review board for human subject studies (Comissão de Ética para Análise de Projetos de Pesquisa - CAPPesq, Hospital das Clínicas, University of Sao Paulo Medical School), and all patients provided written informed consent.

\section{Author details}

${ }^{1}$ Heart Institute, InCor, University of Sao Paulo Medical School, Cardiovascular Magnetic Resonance and Computed Tomography Sector, Av. Dr. Enéas de Carvalho Aguiar, 44, Andar AB, Cerqueira César, São Paulo, SP 05403-000, Brazil. Department of Radiology, Brigham and Women's Hospital, Boston, MA, USA.

Received: 29 July 2016 Accepted: 12 November 2016

Published online: 28 November 2016

\section{References}

1. World Health Organization. Research priorities for Chagas disease, human African trypanosomiasis and leishmaniasis. World Health Organ Tech Rep Ser 2012:v-xii, 1-100.

2. Bern C, Montgomery SP, Herwaldt BL, Rassi A, Marin-Neto JA, Dantas RO, Maquire JH, Acquatella H, Morillo C, Kirchhoff LV, Gilman RH, Reyes PA, Salvatella R, Moore AC. Evaluation and treatment of chagas disease in the United States: a systematic review. JAMA. 2007;298:2171-81.

3. Guerri-Guttenberg RA, Grana DR, Ambrosio G, Milei J. Chagas cardiomyopathy: Europe is not spared! Eur Heart J. 2008:29:2587-91.

4. Bocchi EA. Heart failure in South America. Curr Cardiol Rev. 2013;9:147-56.

5. Rassi A, Little WC, Xavier SS, Rassi SG, Rassi AG, Rassi GG, Hasslocher-Moreno A, Sousa AS, Scanavacca MI. Development and validation of a risk score for predicting death in Chagas' heart disease. N Engl J Med. 2006;355:799-808.

6. Rochitte CE, Oliveira PF, Andrade JM, lanni BM, Parga JR, Avila LF, Kalil-Filho R, Mady C, Meneghetti JC, Lima JAC, Ramires JAF. Myocardial delayed enhancement by magnetic resonance imaging in patients with Chagas' disease: a marker of disease severity. J Am Coll Cardiol. 2005;46:1553-8.

7. Regueiro A, García-Álvarez A, Sitges M, Ortiz-Pérez JT, De Caralt MT, Pinazo MJ, Posada E, Heras M, Gascón J, Sanz G. Myocardial involvement in Chagas disease: insights from cardiac magnetic resonance. Int J Cardiol. 2013;165:107-12.

8. Torreão JA, lanni BM, Mady C, Naia E, Rassi CH, Nomura C, Parga JR, Avila LF Ramires JAF, Kalil-Filho R, Rochitte CE. Myocardial tissue characterization in Chagas' heart disease by cardiovascular magnetic resonance. J Cardiovasc Magn Reson. 2015;17:97.

9. Yang Y, Chen L, Yam Y, Achenbach S, Al-Mallah M, Berman DS, Budoff MJ, Cademartiri F, Callister TQ, Chang HJ, Cheng VY, Chinnaiyan K, Cury R, Delago A, Dunning A, Feuchtner G, Hadamitzky M, Hausleiter J, Karlsberg RP, Kaufmann PA, Kim YJ, Leipsic J, Labounty T, Lin F, Maffei E, Raff GL, Shaw LJ, Villines TC, Min JK, Chow BJW. A Clinical model to identify patients with highrisk coronary artery disease. JACC Cardiovasc Imaging. 2015;8:427-34.

10. Shikanai-Yasuda MA, Carvalho NB. Oral transmission of Chagas disease. Clin Infect Dis. 2012;54:845-52.

11. Bastos CJC, Aras R, Mota G, Reis F, Dias JP, de Jesus RS, Freire MS, de Araújo EG, Prazeres J, Grassi MFR. Clinical outcomes of thirteen patients with acute chagas disease acquired through oral transmission from two urban outbreaks in northeastern Brazil. PLoS Negl Trop Dis. 2010;4:e711.

12. Schulz-Menger J, Bluemke DA, Bremerich J, Flamm SD, Fogel MA, Friedrich MG, Kim RJ, von Knobelsdorff-Brenkenhoff F, Kramer CM, Pennell DJ, Plein S, Nagel E. Standardized image interpretation and post processing in cardiovascular magnetic resonance: Society for Cardiovascular Magnetic Resonance (SCMR) Board of Trustees Task Force on Standardized Post Processing. J Cardiovasc Magn Reson. 2013;15:35. doi:10.1186/1532-429X-15-35.

13. Perez-David E, Arenal A, Rubio-Guivernau JL, del Castillo R, Atea L, Arbelo E, Caballero E, Celorrio V, Datino T, Gonzalez-Torrecilla E, Atienza F, LedesmaCarbayo MJ, Bermejo J, Medina A, Fernández-Avilés F. Noninvasive identification of ventricular tachycardia-related conducting channels using contrast-enhanced magnetic resonance imaging in patients with chronic myocardial infarction: comparison of signal intensity scar mapping and endocardial voltage mappin. J Am Coll Cardiol. 2011;57:184-94. 
14. Bello D, Fieno DS, Kim RJ, Pereles FS, Passman R, Song G, Kadish AH, Goldberger JJ. Infarct morphology identifies patients with substrate for sustained ventricular tachycardia. J Am Coll Cardiol. 2005;45:1104-8.

15. Yan AT, Shayne AJ, Brown KA, Gupta SN, Chan CW, Luu TM, Di Carli MF, Reynolds HG, Stevenson WG, Kwong RY. Characterization of the peri-infarct zone by contrast-enhanced cardiac magnetic resonance imaging is a powerful predictor of post-myocardial infarction mortality. Circulation. 2006;114:32-9.

16. Baron $\mathrm{R}$, Kenny $\mathrm{D}$. The moderator-mediator variable distinction in social psychological research. J Pers Soc Psychol. 1986;51:1173-82.

17. Sobel ME. Asymptotic confidence intervals for indirect effects in structural equation models. Sociol Methodol. 1982;13:290-312.

18. Kawel-Boehm N, Maceira A, Valsangiacomo-Buechel ER, Vogel-Claussen J, Turkbey EB, Williams R, Plein S, Tee M, Eng J, Bluemke DA. Normal values for cardiovascular magnetic resonance in adults and children. J Cardiovasc Magn Reson. 2015;17:29.

19. Sabino EC, Ribeiro AL, Salemi VMC, Di Lorenzo OC, Antunes AP, Menezes MM, lanni BM, Nastari L, Fernandes F, Patavino GM, Sachdev V, Capuani L, de Almeida-Neto C, Carrick DM, Wright D, Kavounis K, Goncalez TT, Carneiro-Proietti AB, Custer B, Busch MP, Murphy EL. Ten-Year Incidence of Chagas Cardiomyopathy Among Asymptomatic Trypanosoma cruziSeropositive Former Blood Donors. Circulation. 2013:127:1105-15.

20. Marin-Neto JA, Cunha-Neto E, Maciel BC, Simões MV. Pathogenesis of chronic Chagas heart disease. Circulation. 2007;115:1109-23.

21. Bilate $A M B$, Salemi VMC, Ramires FJA, de Brito T, Silva AM, Umezawa ES, Mady C, Kalil J, Cunha-Neto E. The Syrian hamster as a model for the dilated cardiomyopathy of Chagas' disease: a quantitative echocardiographical and histopathological analysis. Microbes Infect. 2003:5:1116-24.

22. Higuchi ML, De Morais CF, Pereira Barreto AC, Lopes EA, Stolf N, Bellotti G, Pileggi $F$. The role of active myocarditis in the development of heart failure in chronic Chagas' disease: a study based on endomyocardial biopsies. Clin Cardiol. 1987;10:665-70.

23. Kalil R, Bocchi EA, Ferreira BM, de Lourdes Higuchi M, Lopes NH, Magalhães AC, Mady C, Pereira Barretto AC, Albuquerque CP, Bellotti G. Magnetic resonance imaging in chronic Chagas cardiopathy. Correlation with endomyocardial biopsy findings. Arq Bras Cardiol. 1995;65:413-6. Portuguese.

24. do Prado júnior JC, Leal Mde P, Anselmo-Franci JA, de Andrade júniur HF, Kloetzel JK. Influence of female gonadal hormones on the parasitemia of female Calomys callosus infected with the " $Y$ " strain of Trypanosoma cruzi. Parasitol Res. 1998:84:100-5.

25. Schuster JP, Schaub GA. Trypanosoma cruzi: the development of estrus cycle and parasitemia in female mice maintained with or without male pheromones. Parasitol Res. 2001;87:985-93.

26. Kubanek M, Sramko M, Maluskova J, Kautznerova D, Weichet J, Lupinek P, Vrbska J, Malek I, Kautzner J. Novel predictors of left ventricular reverse remodeling in individuals with recent-onset dilated cardiomyopathy. J Am Coll Cardiol. 2013;61:54-63

27. Masci PG, Schuurman R, Andrea B, Ripoli A, Coceani M, Chiappino S, Todiere G, Srebot V, Passino C, Aquaro GD, Emdin M, Lombardi M. Myocardial fibrosis as a key determinant of left ventricular remodeling in idiopathic dilated cardiomyopathy: A contrast-enhanced cardiovascular magnetic study. Circ Cardiovasc Imaging. 2013:6:790-9.

28. Ambale Venkatesh B, Volpe GJ, Donekal S, Mewton N, Liu C-Y, Shea S, Liu K, Burke G, Wu C, Bluemke DA, Lima JAC. Association of longitudinal changes in left ventricular structure and function with myocardial fibrosis: the MultiEthnic Study of Atherosclerosis study. Hypertension. 2014;64:508-15.

29. Iles L, Pfluger H, Lefkovits L, Butler MJ, Kistler PM, Kaye DM, Taylor AJ. Myocardial fibrosis predicts appropriate device therapy in patients with implantable cardioverter-defibrillators for primary prevention of sudden cardiac death. J Am Coll Cardiol. 2011;57:821-8.

30. Neilan TG, Farhad H, Mayrhofer T, Shah RV, Dodson JA, Abbasi SA, Danik SB, Verdini DJ, Tokuda M, Tedrow UB, Jerosch-Herold M, Hoffmann U, Ghoshhajra BB, Stevenson WG, Kwong RY. Late gadolinium enhancement among survivors of sudden cardiac arrest. JACC Cardiovasc Imaging. 2015;8:414-23.

31. Kuruvilla S, Adenaw N, Katwal AB, Lipinski MJ, Kramer CM, Salerno M. Late gadolinium enhancement on cardiac magnetic resonance predicts adverse cardiovascular outcomes in nonischemic cardiomyopathy: a systematic review and meta-analysis. Circ Cardiovasc Imaging. 2014;7:250-8.

32. de Mello RP, Szarf G, Schvartzman PR, Nakano EM, Espinosa MM, Szejnfeld D, Fernandes V, Lima JAC, Cirenza C, De Paola AAV. Delayed enhancement cardiac magnetic resonance imaging can identify the risk for ventricular tachycardia in chronic Chagas' heart disease. Arq Bras Cardiol. 2012;98:421-30.
33. Wu KC, Gerstenblith G, Guallar E, Marine JE, Dalal D, Cheng A, Marbán E, Lima JAC, Tomaselli GF, Weiss RG. Combined cardiac magnetic resonance imaging and C-reactive protein levels identify a cohort at low risk for defibrillator firings and death. Circ Cardiovasc Imaging. 2012;5:178-86.

34. Hoff R, Mott KE, Silva JF, Menezes V, Hoff JN, Barrett TV, Sherlock I. Prevalence of parasitemia and seroreactivity to Trypanosoma cruzi in a rural population of Northeast Brazil. Am J Trop Med Hyg. 1979;28:461-6.

\section{Submit your next manuscript to BioMed Central and we will help you at every step:}

- We accept pre-submission inquiries

- Our selector tool helps you to find the most relevant journal

- We provide round the clock customer support

- Convenient online submission

- Thorough peer review

- Inclusion in PubMed and all major indexing services

- Maximum visibility for your research

Submit your manuscript at www.biomedcentral.com/submit
C Biomed Central 